ISSN:

Print - $2277-0755$

Online - $2315-7453$

(c) FUNAAB 2019

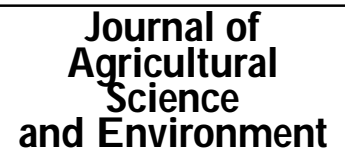

\title{
EFFECTS OF COOKING CONDITIONS ON THE TEXTURE PROFILE, SENSORY AND PROXIMATE QUALITIES OF PRESSURE COOKED BAMBARA NUTS
}

\author{
1*H.A. BAKARE, 1M.0. ADEGUNWA, 2R.A. AKERELE, 3A.0. TIJANI, 10.0. \\ ALAKE, 1I.I. ILUGBAMI, 1E.A. FAKEHINDE AND 10.0. OLOYEDE \\ 1D epartment of Hospitality and Tourism, Federal University of Agriculture, Abeokuta, \\ Nigeria. \\ 2D epartment of Home Economics and Hotel Management, Tai Solarin University of \\ Education, Ijagun, Ijebu-O de , Nigeria. \\ 3D epartment of Food Science and technology, Federal University of Agriculture, \\ A beokuta, Nigeria.
}

*Corresponding Author: bakare65@gmail.com

Tel: +2348052678026

\begin{abstract}
This study evaluated the effects of pressure cooking on the textural attributes of Bambara nuts using Response Surface Methodology (RSM).The study optimized cooking condition \{Weight of Bambara $(250-1000 \mathrm{~g})$, cooking time (20 -90 $\mathrm{min})$ and post cooking resident time (2-12 min)\} for the pressure boiling on the textural and qualities of Bambara. Five out of the eleven optimised solutions (Desirability Index range of 0.919 to 0.936 ) were compared with samples from conventionally boiled Bambara for proximate and sensory (colour, texture, aroma and Overall acceptance) qualities. Data were analysed using RSM, analysis of variance and PPMC. Models for hardness, springiness, cohesiveness, fracturability and sensory texture with adjusted $\mathrm{R}^{2}$ values of $83.41 \%, 80.99 \%, 67.37 \%, 93,75 \%$ and 88.96\% respectively adequately explained the textural and sensory qualities of boiled bambara. The range of values for moisture, fat, ash, crude protein and carbohydrate were 47.88, 2.24, 1.98, 24.30, $20.91 \%$ to $50.58,2.58,2.19,25.49,21.87 \%$ respectively. Boiled Bambara produced at verified optimisation solutions (527.62g, 82.55, $10.43 \mathrm{~min}$ and $591.69 \mathrm{~g}, 82.96,9.52$ minutes) were not significantly different $(p>0.05)$ from that produced by conventional method (weight and Cooking time: $500 \mathrm{~g}$ and $125 \mathrm{~min}$.) in spite of the relatively longer cooking time of the later.
\end{abstract}

Keywords: Food production, Maize, Culinary attributes, Ogi,

\section{INTRODUCTION}

Bambara nut is a neglected and underutilized legumes that is cultivated mostly by rural farmers. Like most legumes, it is one of the most important sources of macronutrients for rural households. It has been ranked in most West African countries as the third most important grain legume after groundnuts and cowpea (Padulosi et al. 2002; Adegunwa et al., 2013). It is droughts tolerant, easy to cultivate crop but under cultivated and underutilized due partly to its hard to cook phenomenon (Bamshaiye,et al., 
2011 ; D enis et al., 2015 and Mubaiwa, et al., 2016). The Bambara groundnut, or round beans is known by various names in different parts of Africa; ClôNgô (among the Akan tribes of Côte d'Ivoire- Denis et al., 2015), jugo beans (South Africa), ntoyo ciBemba (Republic of Zambia), Gurjiya or Kwaruru (Hausa, Nigeria), O kpa (Ibo, Nigeria), Epa-Roro (Yoruba, Nigeria) and Nyimo beans (Zimbabwe).

Bambara groundnut is eaten in several ways and at different stages of maturation. The fresh seeds may be boiled and eaten as a snack in a manner similar to boiled peanuts (Plahar et al., 2002; Hillocks et al., 2011 and Ani et al., 2013). It could also be made into pudding locally called moin moin or okpa (Bean porridge) in some parts of Nigeria. The flour has been used to improve the nutritional values of bread (Okpuzor et al. 2010), preparation of nut milk (Poulter and Caygill, 2006), thin and stiff porridge (Amarteifio and Moholo , 1998 ; Mubaiwa et al., 2017). In some parts of East Africa, the flour of roasted Bambara groundnuts are used to make soup and relishes while the roasted nuts are also used as substitute for coffee. (Onwuka and Abasiekong, 2006).

Boiling, stewing and roasting are some of the most common methods of cooking legumes in West Africa. Boiling is a base method of cooking for most leguminous dishes. Most types of African bean soups and porridges are prepared by combination of boiling and stewing. Boiling is an easy and quick method of cooking and does not require constant attention, makes food soft and easy to digest and it is suitable for cooking foods for children, invalids, convalescents, and the aged. Many types of foods can be cooked in this way and liquids obtained af- ter boiling can be used for soups and sauces. It is however, a longer method of cooking and consumes relatively more energy than some other methods of cooking. Bambara groundnuts require higher-energy expenditure to cook it to the point of edibility because of the longer time of up to 3-4 hours (Mubaiwa et al., 2017) that it takes to soften the seed compared to cowpea or common bean Hillocks et al., 2011). This has been attributed to the hard to cook phenomenon (HTCP) in Bambara groundnut. Several factors have been adduced for the HTCP. The hot and humid conditions under which legumes are stored in many subtropical and tropical African countries make Bambara nut to be prone to a hardening phenomenon associated with modifications that occur in the cotyledons and seed coats (Mubaiwa et al., 2017; Stanley and Aguilera, 1985). This is characterized by extended cooking time (Coelho et al., 2007; Garcia et al., 1998). Though, it may be possible to arrest the development of the HTCP in legumes by exploring low temperature and humidity options (Hentges et al., 1991; Garcia et al., 1998), but the economic and social sustainability of storing the legume under refrigeration condition at domestic and industrial level is likely to be more challenging. Adoption of suitable processing technologies therefore seems to be a more feasible option but this may not also be versatile for most culinary operations. Processing technologies that have been explored in tackling the HTCP included the use of chemical pre-treatments, biological (germination and fermentation), and physical (milling, roasting and canning) treatments. However, information on the use of novel cooking methods like pressure cooking is very scarce. Pressure cooking may reduce drudgery; cooking time and also saves fuel and energy. 
EFFECTS OF CO OKING CONDITIONS ON THE TEXTURE PROFILE, SENSORY ...

In Pressure cooking, food is cooked in a pressure cooker which is a sealed vessel that does not permit air or liquids to escape below a pre-set pressure. The food is cooked more quickly than the conventional method because the trapped steam in the cooker increases the internal pressure and temperature. Pressure pots are versatile, affordable and accessible to both urban and rural households. However, the adoption of pressure cooking for the boiling of Bambara nuts requires the standardisation of the cooking conditions and the identification of characteristics that may be applicable to various uses of the pulse. This study therefore evaluated the effects of pressure cooking on the textural attributes of Bambara nuts using Response Surface Methodology (RSM). Specifically, the study assessed the effect of weight of Bambara, cooking time, and post cooking time (Resident time) on the textural attributes of Bambara. It also assessed the sensory qualities and proximate compositions of some of the optimized solutions.

\section{MATERIALS AND METHODS}

\section{Materials}

Brown Bambara seeds (Vigna subterranean) were purchased from a retail market in O deda Local Government Area, Ogun State, Nigeria.

\section{Methods}

Pressure boiling of B ambara groundnut

A domestic pressure pot (Model PC500, 5.5 litter capacity (Black \& D ecker: 1910, Baltimore, Maryland, United States) was used for the experiments. The Bambara seeds were sorted and sieved to remove shaft and other dirt. It was immersed in about $14.3 \%$ (w/ w) of water, boiled under pressure for the required length of cooking time.

\section{Design of the study}

Box-Behnken design (Box and Behnken, 1960) was used for the experiment. The three independent variables used for the process optimisation were Weight of Bambara seeds (X1: 25 to $1000 \mathrm{~g}$ ), cooking time (X2: 20 to $90 \mathrm{~min}$ ) and post cooking time (X3: 2 to $12 \mathrm{~min})$. The range of values used for each of the independent variables (Table 1) was based on preliminary experiments. The design consisted of 17 generated experimental runs to which the dependent variables (Responses) were fitted after the laboratory experiments. The measured responses were textural (Hardness, springiness, adhesiveness, cohesiveness, chewiness, fracturability, gumminess, energy to break and stringiness) and sensory (colour, taste, texture, aroma and overall acceptability). Optimisation criteria were set (Table 2). The sensory and proximate qualities of optimised pressure cooked boiled seeds with five best desirability value were compared with conventionally cooked reference sample.

\section{Determination of texture profiles of cooked Bambara}

The texture profile of the cooked Bambara kernels were measured using Food compression test with the aid of Testometric material testing machine (Machine model No. 050010080, Testometric Co., United Kingdom, Lancashire, England ol11 1NR) The test distance of $0.50 \mathrm{~mm}$ was selected after careful consideration of stickiness and adhesiveness of the product. The cooked samples were subjected to compressive force by the probe up to the distance of $0.50 \mathrm{~mm}$ for two times resulting in two curves. The condition-set up in the Texture Analyser for measuring textural properties was as follows: speed: 102 $\mathrm{mm} / \mathrm{min}$; preload test speed: $60.000 \mathrm{~mm} /$ min; posttest speed: $1.0 \mathrm{~mm} / \mathrm{s}$; count: 2; deflection (mm): $3 \mathrm{~mm}$ (50\% Strain); preload 
(trigger) force $0.50 \mathrm{~N}$; break sensitivity: 0.20 $\mathrm{N}$; acquisition rate: $200 \mathrm{pps}$; load cell: $50 \mathrm{~kg}$; probe diameter $(\mathrm{mm})$ : Every test was replicated a minimum of three times (Fig 6) and mean values for each parameter were calculated.

Texture parameters were determined from the texture profile (Bourne, 1978; Bourne et al., 1978; Rosenthal, 1999). Hardness was calculated as the peak force of the first compression of the product. The cohesiveness, represents how well the product, withstands a second deformation relative to how it behaved under the first deformation. Cohesiveness was calculated as the ratio of the area under second peak to the first peak i.e. A2/ A1 (Fig 1). Springiness was measured by the distance of the detected height of the product on the second compression divided by the original compression distance. Chewiness was measured as a product of hard- ness, cohesiveness, and springiness ( $\mathrm{G}$ upta et al., 2007).

\section{Proximate composition, dry matter con- tents and absorbed water}

Proximate composition, dry matter and crude fibre of the samples were determined by standard procedure according to AOAC (2005) methods.

\section{Sensory evaluation}

Sensory appraisal of the boiled Bambara nuts were carried out using thirty un-trained panellists consisting of staff and students of Federal University of Agriculture Abeokuta, Nigeria. The panellist rated their preference for colour, taste, texture, aroma and general Acceptance of the boiled Bambara samples from the samples using hedonic ratings $(1=$ disliked extremely to $9=$ liked extremely).

Table 1: The coded values for the independent variables

\begin{tabular}{lcccc}
\hline Processing variables & Variable & $\mathbf{- 1}$ & $\mathbf{0}$ & $\mathbf{+ 1}$ \\
\hline Mass (g) & (X1) & 250.00 & 625.00 & 1000.00 \\
Cooking time (min) & (X2) & 20.00 & 55.0 & 90.00 \\
Post cooking cooling resident time & (X3) & 2.00 & 8.50 & 12.00 \\
(min) & & & & \\
\hline
\end{tabular}

\section{Data analysis}

Experimental data were fitted to a second order polynomial model and regression coefficients the various responses were obtained. The generalized second-order polynomial used in response surface analysis was. $Y=\beta_{0}+\beta_{1} x_{1}+\beta_{2} x_{2}+\beta_{3} x_{3}+\beta_{4} x_{1} x_{2}+$ $\beta_{5} x_{1} x_{3}+\beta_{6} x_{2} x_{3}+\beta_{7} x_{1} x_{2} x_{3}+€$

Where $Y$ is the response, $\beta_{0}$ is the intercept, where $\beta_{1}, \beta_{2}$ and $\beta_{3}$ are linear, quadratic and interaction coefficients respectively while , $\mathrm{x}_{1}, \mathrm{x}_{2}, \mathrm{x}_{3}$ are the independent variables and $€$ is the error. The statistical significance of the terms in the regression equations was examined by analysis of variance for each of the responses.

The Design expert software version 7.00 (Stat Ease Inc., Minneapolis, MN, USA), was used to generate response surfaces models graphs showing the relationship between the independent variable and the responses while holding a variable constant. 


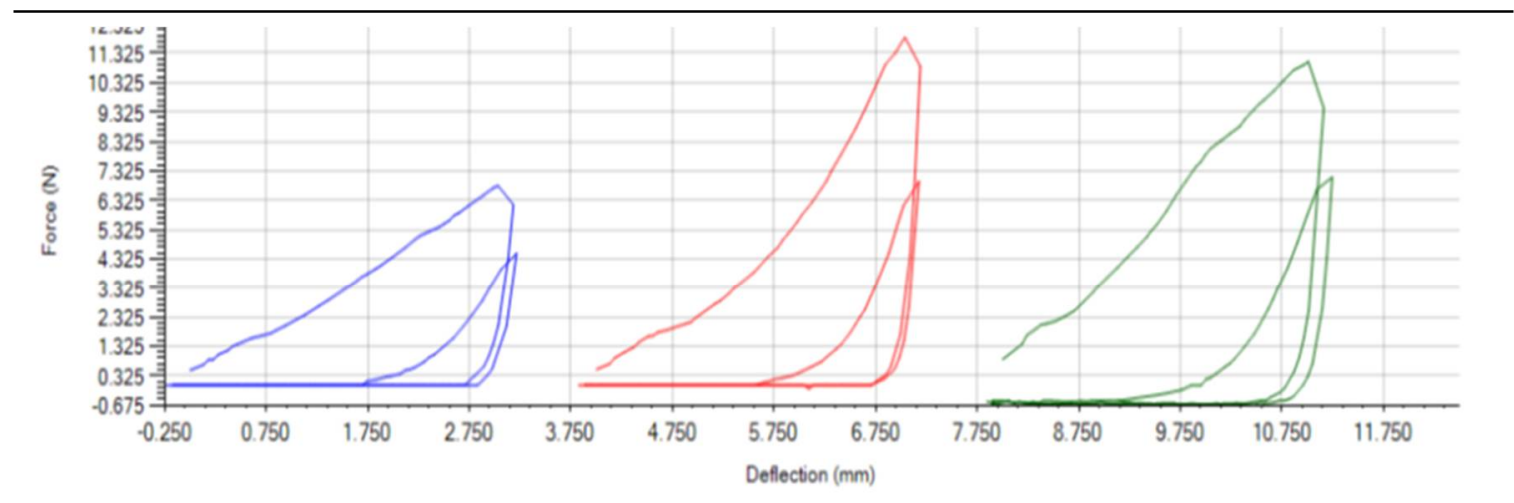

Fig 1 :Typical Texture Curve 0 btained from the Study

Optimisation goals/ constraints were set (Table 2) and the responses were optimized by using the numerical method of RSM based on desirability concept to obtain range of optimised solutions. The adopted solutions were then used for the verification experiments to determine the validity of the model (Bakare et al., 2009).

D ata on the proximate and sensory qualities of pressure and conventionally cooked boiled seeds were compared using analyses of variance and means were separated using D uncan multiple range test. Statistical analysis package software, version 17 for windows was used for the analysis.

\section{RESULTS AND DISCUSSION}

Texture is an important quality attributes in boiled legumes. The various sensors in the mouth, auditory organs and the brain are involved in processing and relating images of textural properties with information from past experiences about the accepted quality of a particular food (Bakare et al., 2018). The growing interest in developing sensory and instrumental technique for evaluating the textural characteristics of food underscores the importance of texture in the quality assessment of foods. Sensorial texture is a primary determinant of the acceptability of cooked legumes like Bambara.

\section{Texture Profile of Cooked Bambara nuts $H$ ardness}

The measured response for hardness (Table 3 ) indicated that the lowest $(5.13 \mathrm{~N})$ and highest $81.16 \mathrm{~N}$ were obtained when the weight of Bambara, cooking and cooling time were $250 \mathrm{~g}, 55.00 \mathrm{~min}, 12.00 \mathrm{~min}$ and $625 \mathrm{~g}, 20.00 \mathrm{~min}$ and $2.00 \mathrm{~min}$ respectively. Hardness, in this case, is an indication of the force required to compress a food between the molars (Rosenthal, 1999; Scott-Blair, 1958), it simulate the conditions to which the material is subjected to in the mouth. The lower the hardness values the softer the kernel of the cooked Bambara nut. The differences in relative hardness between lowest and highest values suggested that weight might be a factor for the attainment of edibility at constant cooking and post cooling time. 
Table 2: Constraints to optimization of process variables

\begin{tabular}{lllll}
\hline Constraints & Goal & Lower limit & Upper limit & Importance \\
\hline Mass $\left(\mathbf{X}_{\mathbf{1}}\right)$ & range & 250 & 1000 & 3 \\
Cooking time $\left(\mathbf{X}_{\mathbf{2}}\right)$ & range & 20 & 90 & 3 \\
Holding / Post cooking & & & & \\
time( $\left.\mathbf{X}_{3}\right)$ & range & 2 & 12 & 3 \\
Hardness & minimize & 5.13 & 81.16 & 3 \\
springiness & minimize & 0.10 & 0.39 & 3 \\
Adhesiveness & range & -0.004 & 11.97 & 3 \\
Cohessiveness & range & 0.059 & 0.349 & 3 \\
Chewiness & minimize & 0.08 & 5.38 & 3 \\
Fracturability & range & 0.67 & 79.09 & 3 \\
Gumminess & minimize & 0.65 & 21.78 & 3 \\
Energy to break & range & 0.015 & 0.22 & 3 \\
Stringiness & minimize & 4.76 & 8.58 & 3 \\
Colour & maximize & 5.4 & 7.03 & 3 \\
Taste & maximize & 4.63 & 6.63 & 3 \\
Texture & maximize & 4.2 & 6.33 & 5 \\
Aroma & maximize & 5.03 & 6.77 & 3 \\
Overall acceptability & maximize & 5.57 & 6.87 & 3 \\
\hline
\end{tabular}

\section{Springiness}

Springiness organoleptically depicted how well a product physically springs back after it has been deformed during the first compression and has been allowed to wait for the target wait time between strokes. The spring back is measured at the down-stroke of the second compression. The lowest (0.10) and highest 0.39 were obtained when the weight of Bambara, cooking and cooling time were $625 \mathrm{~g}, 55.00 \mathrm{~min}, 7.00 \mathrm{~min}$ and $625 \mathrm{~g}, 20.0 \mathrm{~min}$ and $2.00 \mathrm{~min}$ respectively.

\section{Adhesiveness}

Adhesiveness is the work required to pull the food away from a surface of the probe. It is an indication of the extent of stickiness of products. It is the work required to overcome the sticky forces between the sample and the probe (Trinh and Glasgow, 2012). Adhesion is measured as the negative work between the two cycles; however, in many instances the product has stuck to the probe and does not actually separate when the highest point between the two cycles is just back to the original product height. The lowest (0.00 N.S) and highest (11.97 N.S) were obtained when the weight of Bambara, cooking and cooling time were $625 \mathrm{~g}, 20.00$ $\mathrm{min}, 12.00 \mathrm{~min}$ and $1000 \mathrm{~g}, 55.0 \mathrm{~min}$ and $12.00 \mathrm{~min}$ respectively. Higher values of adhesiveness may not necessarily imply that the product may have been over cooked as sample with the highest hardness value was also observed to have the highest adhesiveness values (Table 3) 
EFFECTS OF COOKING CONDITIONS ON THE TEXTURE PROFILE, SENSORY ...

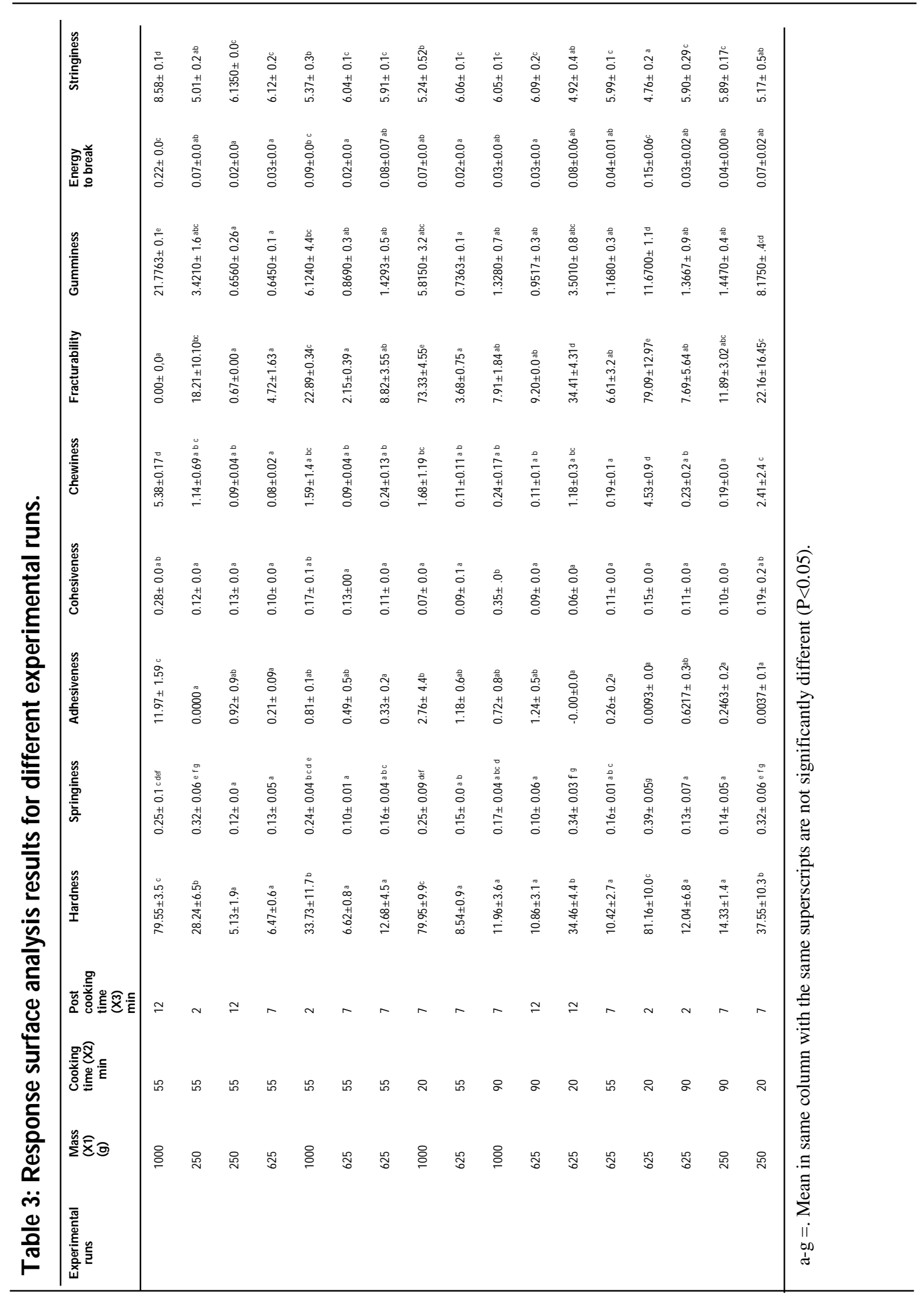

J. Agric. Sci. \& Env. 2019, 19(1\&2): 159-185 165 
Cohesiveness

Cohesiveness reflects the strength of the internal bonds binding the food particles together and suggested how well the cooked Bambara nut withstood a second deformation relative to its resistance under the first deformation. The lowest (0.06) and highest (0.35) were obtained when the weight of Bambara, cooking and cooling time were $625 \mathrm{~g}, 20.00 \mathrm{~min}, 12.00 \mathrm{~min}$ and $1000 \mathrm{~g}, 90.0 \mathrm{~min}$ and $7.00 \mathrm{~min}$ respectively. The cohesiveness of the sample obtained at cooking condition of $1000 \mathrm{~g}, 90.0 \mathrm{~min}$ and $7.00 \mathrm{~min}$ was not significantly different $(\mathrm{p}>$ 0.05 ) from that obtained at $1000 \mathrm{~g}, 55$ minutes , 12 minutes and $1000 \mathrm{~g}, 55$ minutes , 2 minutes respectively but both were significantly $(\mathrm{p}<0.05)$ different from that of other samples.

\section{Chewiness}

Chewiness applies only to solid products and is calculated as the product of gumminess and springiness. It is energy required to chew a solid food till it is ready for swallowing. It is sometimes estimated as the product of Hardness, Cohesiveness and Elasticity, the latter being the extent to which a compressed food returns to its original size when the load is removed (Rosenthal, 1999). The lowest $(0.08 \mathrm{~N})$ and highest $(5.38 \mathrm{~N})$ were obtained when the weight of Bambara, cooking and cooling time were $625 \mathrm{~g}, 55.00 \mathrm{~min}, 7.00 \mathrm{~min}$ and $1000 \mathrm{~g}, 55.0$ min and 12.00 min respectively.

\section{F racturability}

It is the force required to crack the cooked Bambara. It also imitates the first bite force of the seed during at the commencement of chewing. The lowest $(0.00 \mathrm{~N})$ and highest $(73.33 \mathrm{~N})$ were obtained when the weight of Bambara, cooking and cooling time were 1000g, $55.00 \mathrm{~min}, 12.00 \mathrm{~min}$ and
$1000 \mathrm{~g}, 20.0 \mathrm{~min}$ and $7.00 \mathrm{~min}$ respectively. This suggested that Bambara pulses cooked at lower cooking time and held after cooking for less than 12 minutes may require more force to fracture or crack the pulses.

\section{Gumminess}

Gumminess was conceived as the energy required to disintegrate a semi-solid food to make it ready for swallowing ((Trinh and Glasgow, 2012). Gumminess, for most solid product is mutually exclusive with chewiness since such product would not be both a semi -solid and a solid at the same time. This not entirely true for the pressure cooked Bambara nuts boiled in excess water since they may become sticky with sufficient cohesive bond to hold them in place. The lowest $(0.65 \mathrm{~N})$ and highest $(21.78 \mathrm{~N})$ were obtained when the weight of Bambara, cooking and cooling time were $625 \mathrm{~g}, 55.00 \mathrm{~min}, 7.00 \mathrm{~min}$ and $1000 \mathrm{~g}, 55.0 \mathrm{~min}$ and $12.00 \mathrm{~min}$ respectively.

\section{Stringiness}

This is distance travelled by the probe during the negative force area (Trinh and G lasgow, 2012). It is the measured stretched distance of the samples when pulled from the area in which it rest during the test. The lowest (4.76) and highest (6.13) were obtained when the weight of Bambara, cooking and cooling time were $625 \mathrm{~g}, 20.00 \mathrm{~min}, 2.00 \mathrm{~min}$ and $250 \mathrm{~g}, 55.0 \mathrm{~min}$ and $12.00 \mathrm{~min}$ respectively.

Measurement of texture by empirical methods in which forces required to shear, penetrate, compress or cut food are often used as indicators of textural characteristics (Kilcast, 1999; Rosenthal, 1999 and Lawless and Heyman 1998) of food. It is an objective means of assessing the textural quality of food, although, this may not necessarily be regarded as an absolute indicator of texture properties 
EFFECTS OF CO OKING CONDITIONS ON THE TEXTURE PROFILE, SENSORY ...

of food. It has also been argued that not all the textural parameters defined in the Texture Profile Analyses (TPA) test are correct and useful. However, Trinh and Glasgow (2012) suggested such limitation can be reduced through the use of replicated measurements for the same food samples with fairly consistent dimensions and standardised test conditions as used in this study (Fig 7).

The hard to cook phenomenon (HTCP) in Bambara groundnut has been attributed to the hot and humid conditions under which legumes are stored in many subtropical and tropical African countries which made them to be prone to hardening. This phenomenon is associated with modifications that occur in the cotyledons and seed coats (Mubaiwa et al., 2017; Stanley and Aguilera, 1985) which resulted in extended cooking time (Coelho et al., 2007; Garcia et al., 1998). It was further suggested that the hardening of the seeds occurred through structural modifications of the cotyledons and seed coats and also, through compositional changes. Structural modifications has been linked to the autolysis of cytoplasmic organelles, weakling plasmalemma integrity, and lignification of middle lamella while compositional changes has been attributed the formation of insoluble pectate, lipid oxidation, and polymerization, phytic catabolism, interactions of proteins and phenolic compounds and polymerization of phenolic compoundsas well as deposition of ligninlike material. (Garcia et al., 1998, Stanley, 1985, Aguilera and Rivera, 1992).

The mucilage and gums binding the hulls and cotyledons together is broken down during cooking, but at relatively faster rate during high pressure cooking than during conventional cooking. The rate at which the break down occurs in pressure cooking was also dependent on the cooking conditions and Table 3 suggested that this may depend more on the weight of the cooked samples and the time of cooking.

\section{Sensory Attributes of Cooked Bambara nuts}

The range of values for colour, taste, texture, aroma and overall acceptability were 5.40 to $7.03,4.63$ to $6.53,4.20$ to $6.33,5.03$ to 6.77 and 5.57 to 6.87 respectively (Table 4$)$. The samples were significantly different $(p<0.05)$ from each other even at replicated points. The lowest texture score was recorded in 625 $\mathrm{g}$ of the samples cooked 20 minutes and held for 2 minutes while cooling. The highest texture score was recorded in $1000 \mathrm{~g}$ of the samples cooked 55 minutes and held for 12 minutes while cooling (Table 4). The results also indicated that the Bambara needs to be cooked for at least 55 minutes and held for not less than 7 minutes to have soften the Bambara for reasonably high texture scores. Most of the samples were generally acceptable to the panellists. 


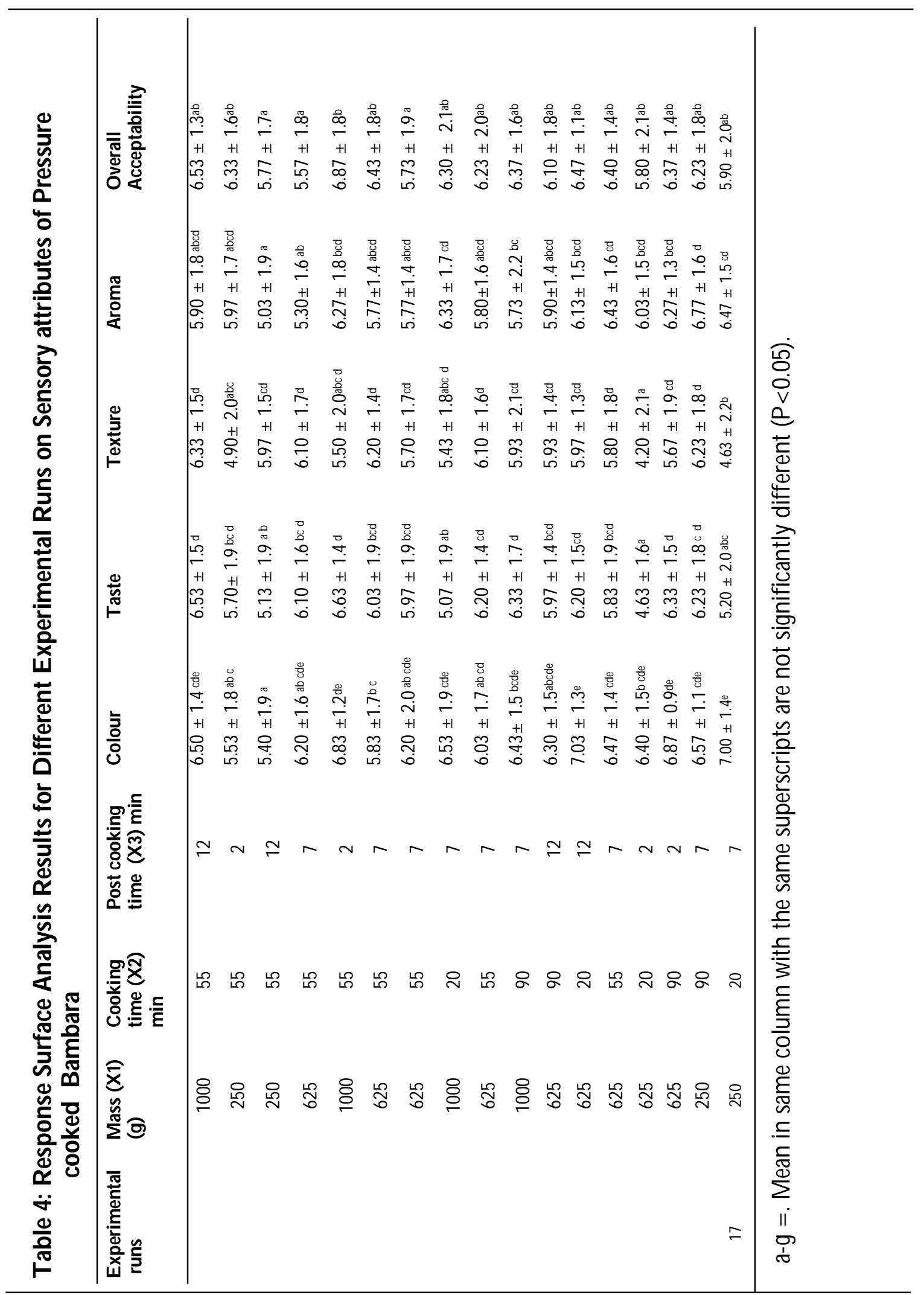




\section{Relationships between Texture Profile Parameters and Sensory Texture of Bambara}

Correlations between sensory texture and the texture profile parameters (Table 5) revealed negative correlation relationships between sensory texture and springiness $(\mathrm{n}=17, \mathrm{r}=-0.733 . \mathrm{p}=0.001)$ as well as fracturability $(n=17, r=-0.673 p=.003)$ but positive relationship with stringiness $(\mathrm{n}=17, \mathrm{r}=0.650 \mathrm{p}=.005)$. These implied that the sensory texture score increased as the stringiness value increases but decreased as the springiness and fracturability values increases. These suggested that sensory panelists preferred cooked Bambara that fractures easily.

\section{Model Descriptions Texture profile}

The optimisation process was carried out by analysing fitness of the model for each of the responses. This was done by testing the fitness of each of the model using the sequential model sum of squares (SMSS). The SMSS indicated the contributions of the linear, two-factor interaction (2FI), quadratic and cubic polynomials terms to the totality of the model.

The SMSS suggested that the Quadratic vs 2FI terms made better (Prob $>\mathrm{F}$ was below 0.05 ) contributions to the model for all the texture parameters (Table 4). This was then used as basis for testing the fitness of the model. The main reason for conducting the fitness test was to identify the model that can best be used as a response predictor. The desire was for the selected model to have insignificant lack-of-fit in order to demonstrate that the model actually fits the data (Myers et al., 2009). This was done by comparing the residual error with the "Pure
Error" from replicated design points. An insignificant lack of fit is indicated by a low probability value ("Prob $>F^{\prime}$ ), low standard deviation, high adjusted R-squared values and a low predicted residual sum of squares (PRESS). The Quadratic model was therefore selected for all the measured texture parameters (Fig 2-6) except stringiness for which the linear model was selected (Table $6)$.

The models were assessed for the adequacy for the experimental conditions and the significant terms in each of the models were identified. Results from the analysis of variance conducted in this respect indicated that model for hardness, springiness, cohesiveness and fracturability were significant (The probability $>F$ were less than 0.05 ) while the models for adhesiveness, chewiness and gumminess were not significant (The probability $>\mathrm{F}$ were greater than 0.1.). There were no significant terms in the model for gumminess, energy to break and stringiness.

The terms in each of these model that were significant for exploration were A (Mass), B (cooking time), AC (Interaction s between mass and cooling time), $\mathrm{A}^{2}$ (exponential function of the Mass) $\mathrm{C}^{2}$ (exponential function of the cooling time) for hardness, the B (cooking time), AC (Interaction s between mass and cooling time) and $\mathrm{C}^{2}$ (exponential function of the cooling time) were the significant terms for springiness. The A (Mass ), $\mathrm{AB}$ (Interactions between mass and cooking time ), $A^{2}$ ( exponential function of the mass of Bambara) for cohesiveness and $\mathrm{A}$, $\mathrm{B}, \mathrm{C}$ ( cooling time) , AB , BC (Interactions between Cooking time and cooling time ), $\mathrm{B}^{2}$ (exponential function of the Cooking time). 


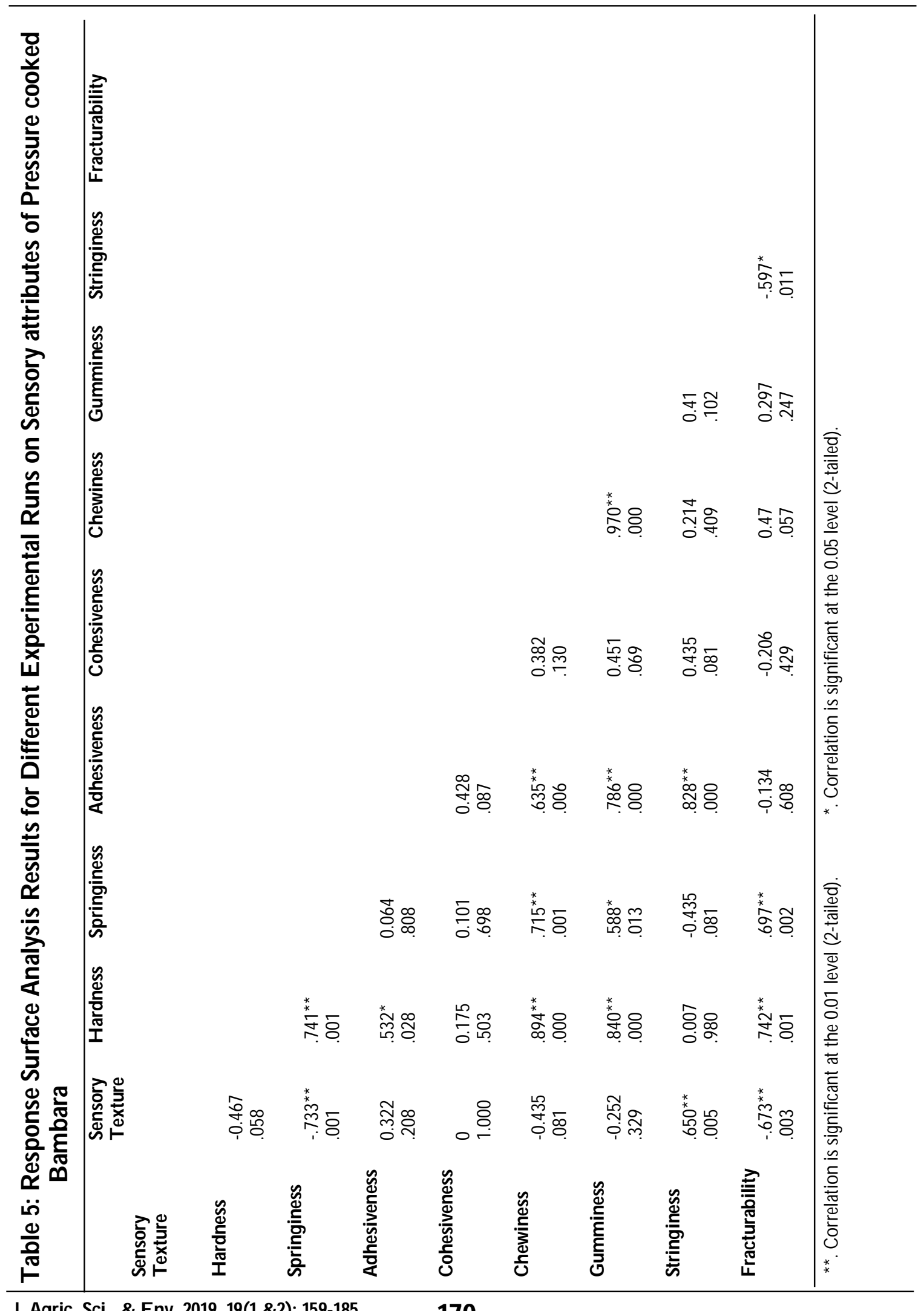

J. Agric. Sci. \& Env. 2019, 19(1\&2): 159-185 170 


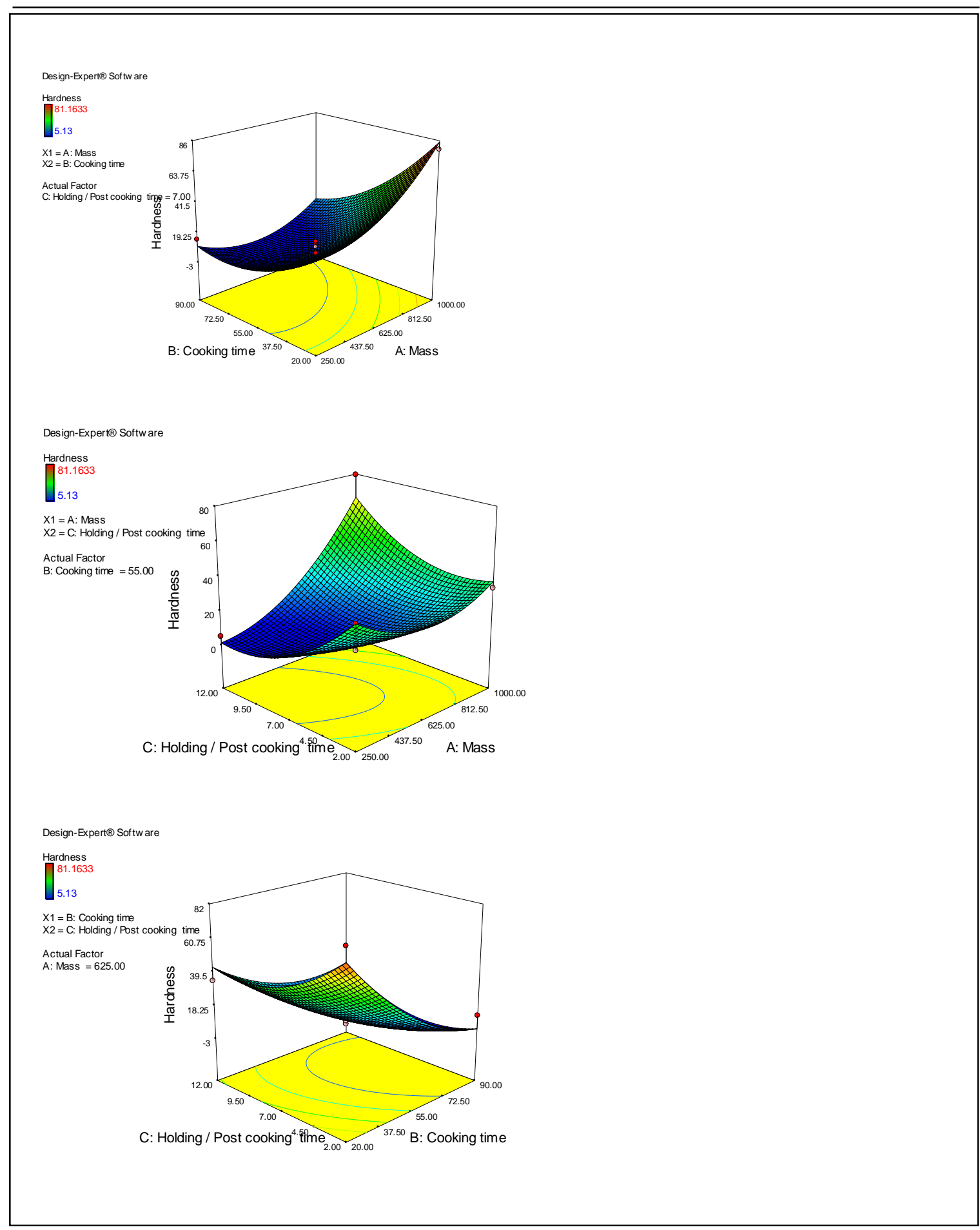

Fig 2: Response Surface Plots of Change in Hardness of Boiled Bambara at Different Experimental conditions. 


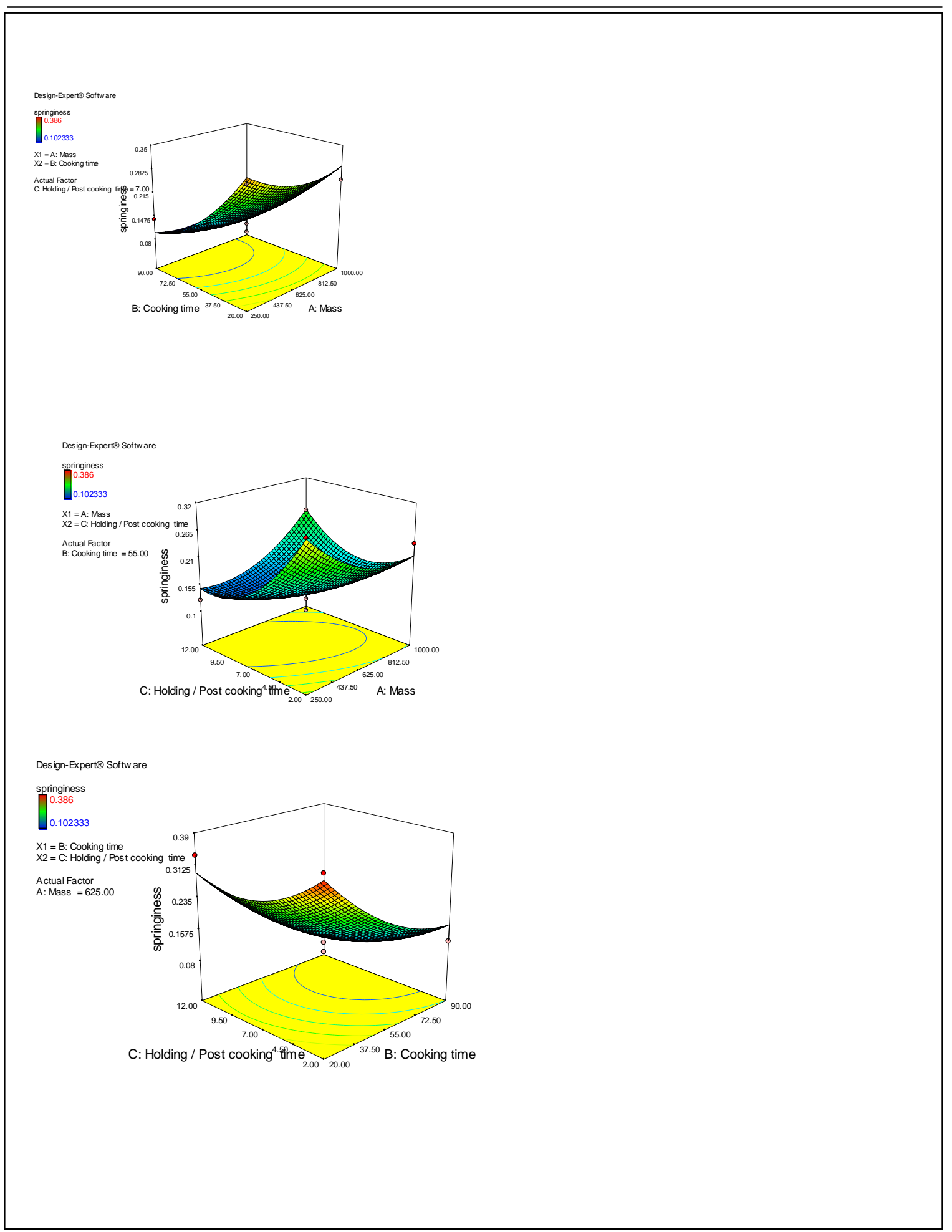

Fig 3 : Response Surface Plots of Change in Springiness of Boiled Bambara at Different Experimental conditions 


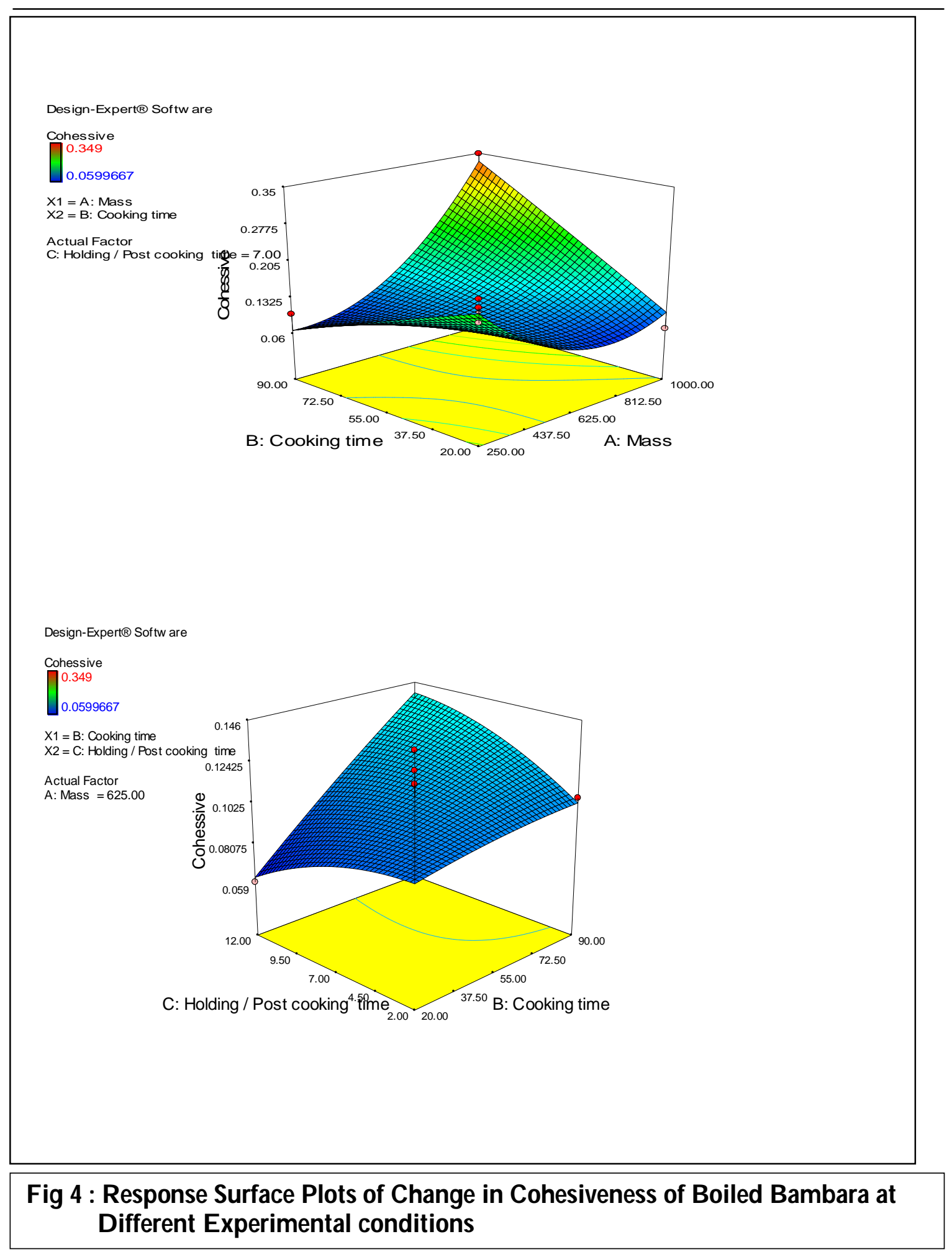




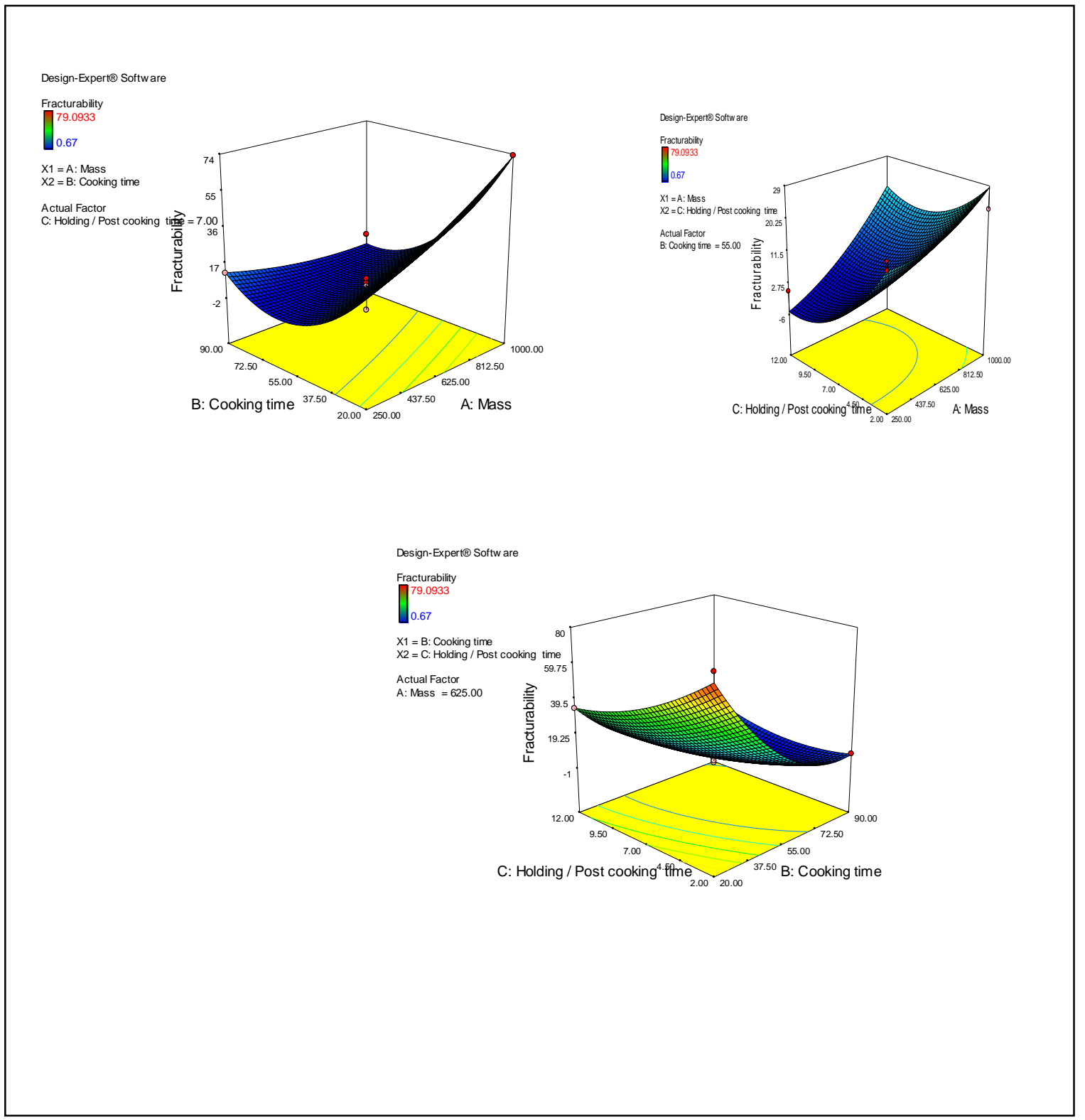

Fig 5 : Response Surface Plots of Fracturability of Boiled Bambara at Different Experimental conditions 


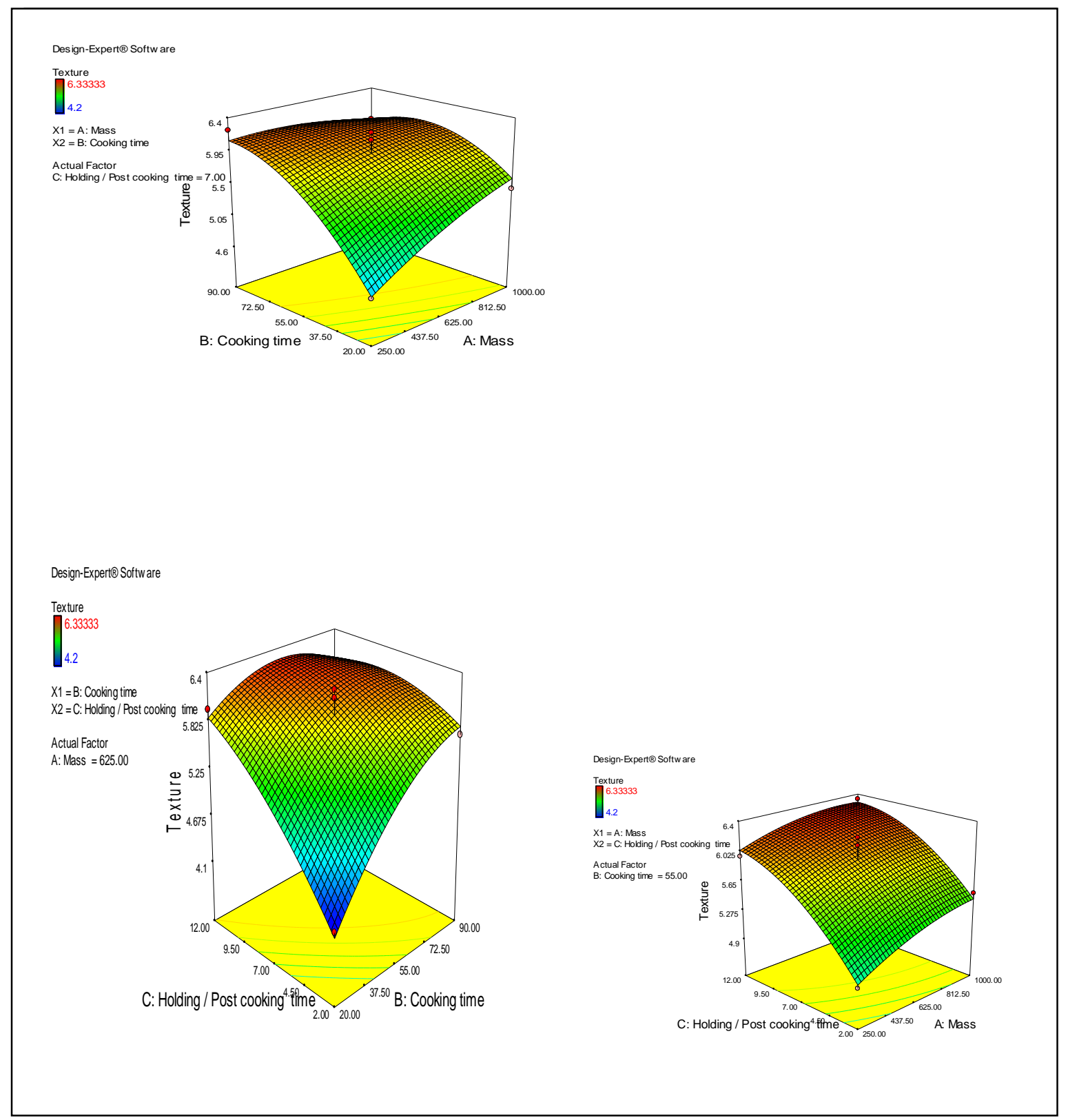

Fig 6 : Response Surface Plots of Sensory Texture of Boiled Bambara at Different Experimental conditions 


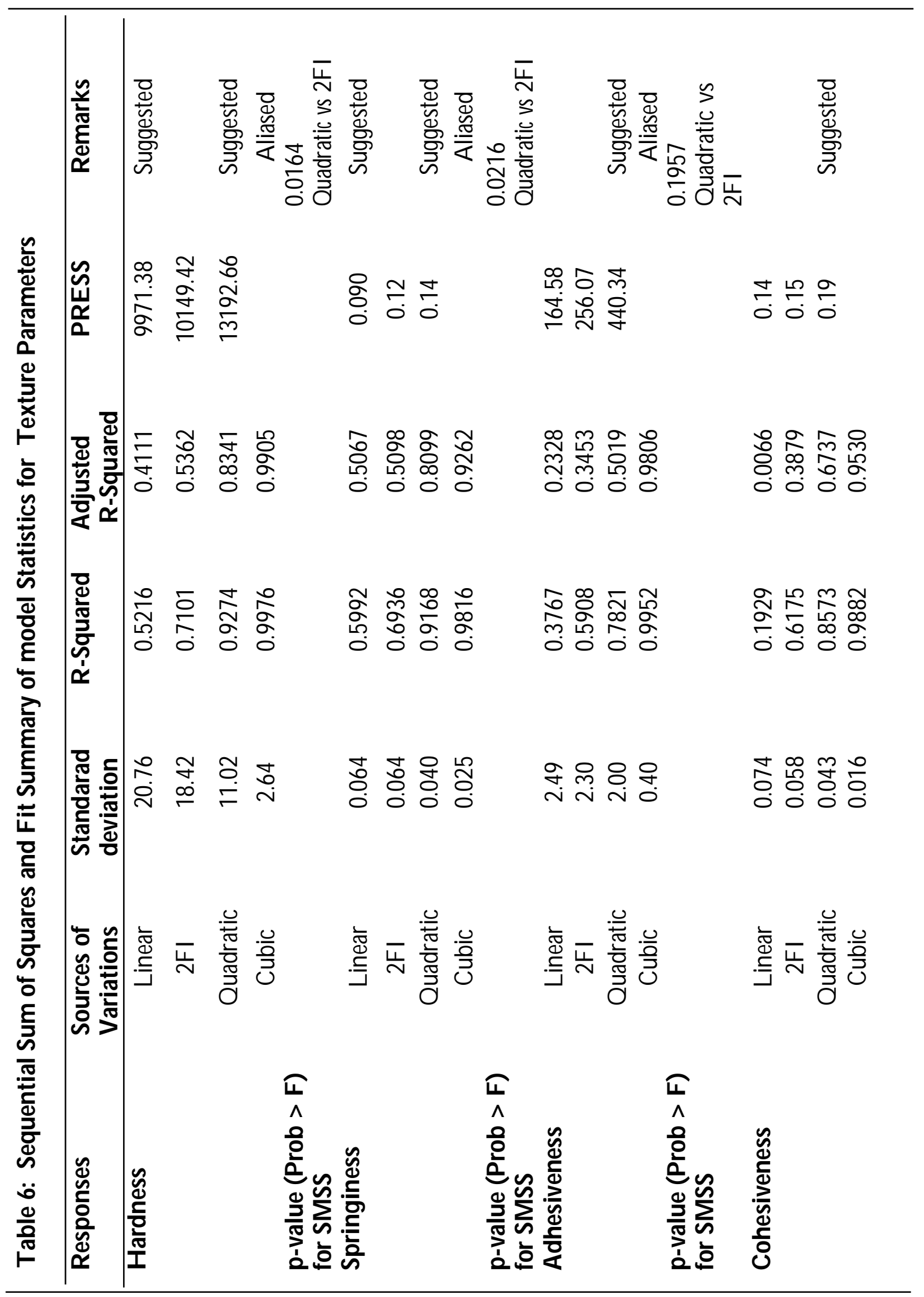




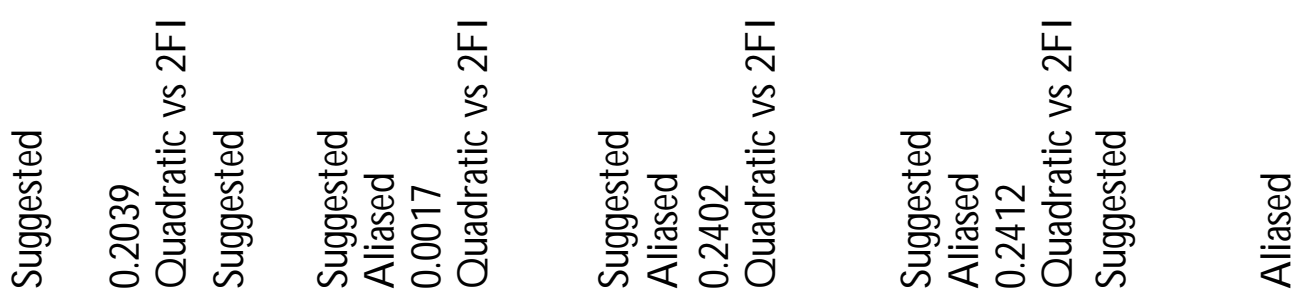

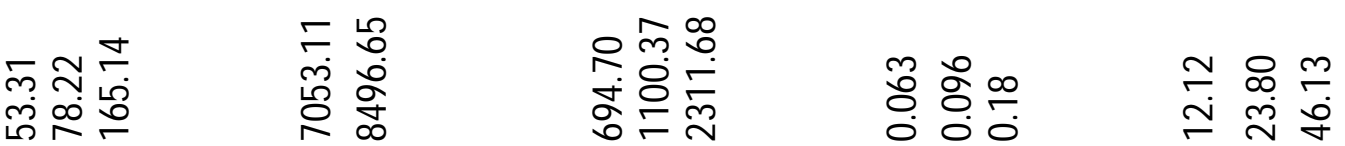

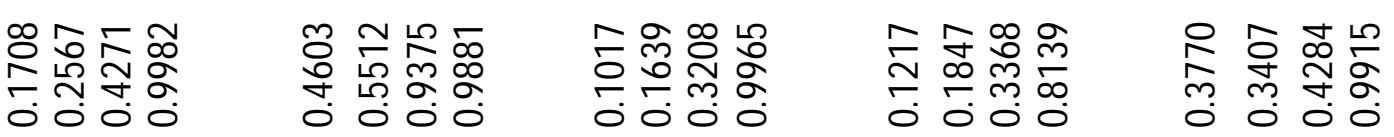

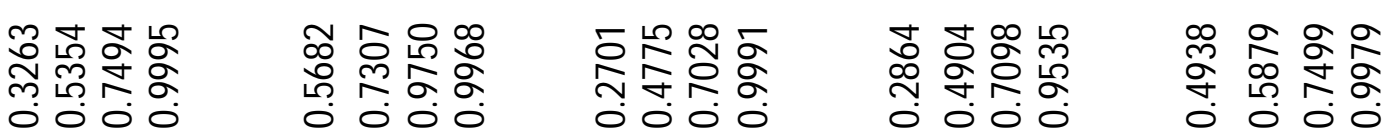

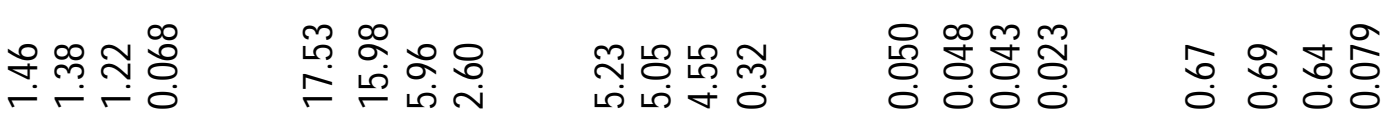

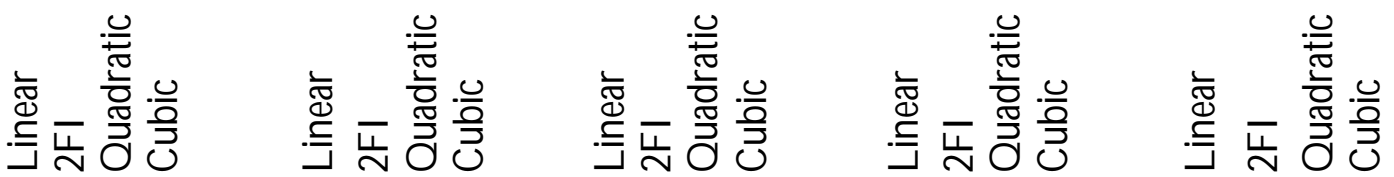

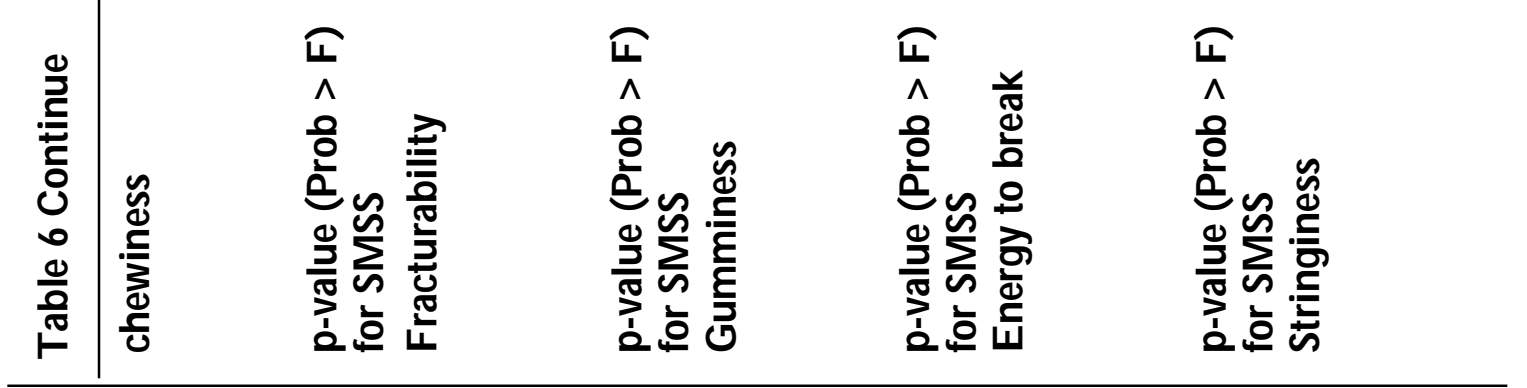




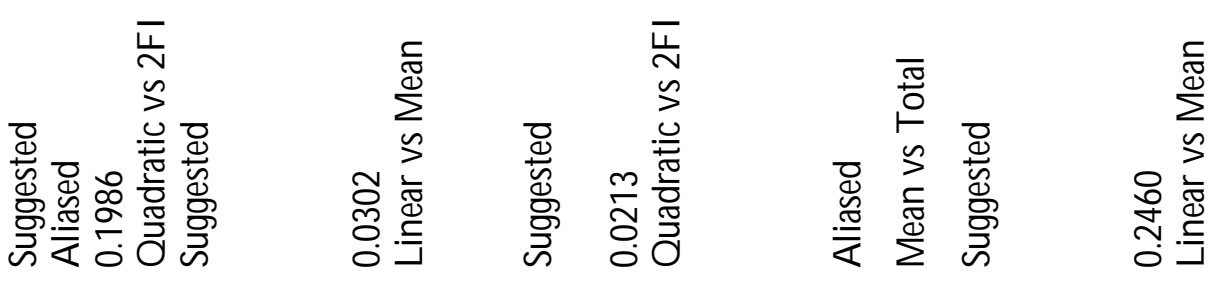

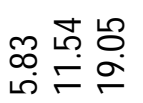

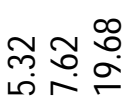
$\begin{array}{lll}\text { m } & 8 & 8 \\ \text { m } & \text { i }\end{array}$

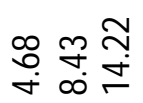

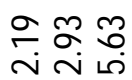

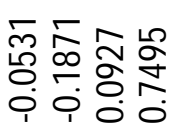

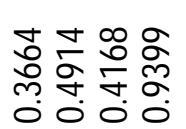

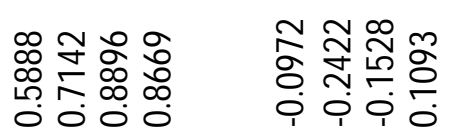

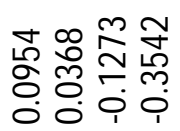

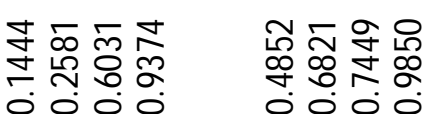

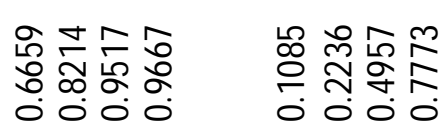

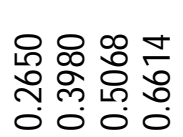

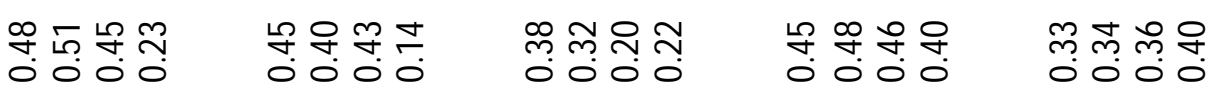

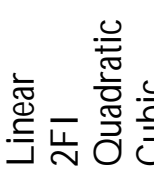<smiles>O=S(=O)(O)O[Na]</smiles><smiles>O=S(=O)(O)O[Na]</smiles><smiles>O=S(=O)(O)O[Na]</smiles><smiles>O=S(=O)(O)O[Na]</smiles>

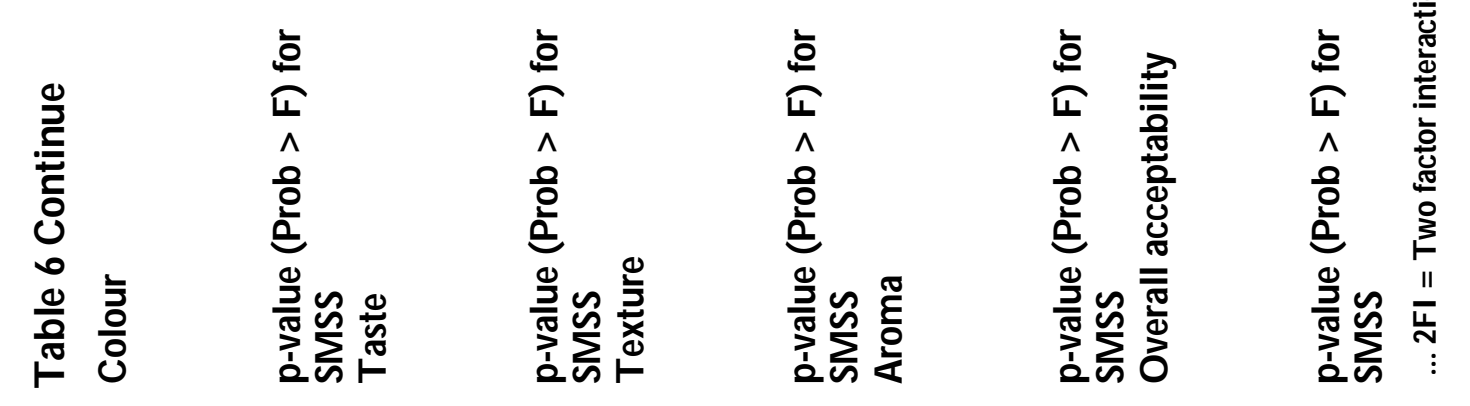


EFFECTS OF CO OKING CONDITIO NS ON THE TEXTURE PROFILE, SENSORY ...

The regression coefficients therefore confirmed that the models for hardness, springiness, cohesiveness and fracturability were the best responses for the processing conditions with adjusted $\mathrm{R}^{2}$ of $83.41 \%, 80.99 \%$, $67.37 \%$ and $93,75 \%$ (Table 7) respectively. The graphs for the responses are indicated in Fig 1-5. The graphs for instance indicated that the hardness value of the cooked Bambara nut decreased with increase in cooking time but increased with the weight of the Bambara (Fig 2).

\section{Sensory profile}

The model properties for sensory properties ( Table 8) indicated that only the models for texture were significantly adequate for exploration and had model terms that can be explored. The adjusted $\mathrm{R}^{2}$ and predicted error sum square (PRESS ) of $88.96 \%$ and 1.65 respectively indicated texture was the most distinguished sensory characteristics of the pressure cooked Bambara. This is not unexpected since the attainment of suitable texture characteristics is a pre-requisite for subsequent uses to which the Bambara might be put.

\section{Targets for $\mathbf{N}$ umerical $\mathbf{O}$ ptimization}

Setting of targets for optimisation was important to getting appropriate numerical optimisation solution. A reasonable understanding of the importance of each of the responses to the textural quality of Bambara nut was necessary for the elimination of irrelevant constraints in the optimisation process and for the setting optimisation goals. In view of this, the optimisation goal for hardness, springiness, chewiness, gumminess and stringiness were set at minimum while other parameters were set within the range of their values (Table 2). This was considered necessary so that the experimental conditions would be able to capture the different culinary uses for boiled Bambara nut.

In Nigeria, cooking by boiling is an intermediate processing activity in the preparation of most African dishes. Many of these dishes have specific range of functional and organoleptic culinary attributes. Bambara is consumed mostly in boiled form or as porridge, attainment of suitable textural characteristics during the boiling stage usually serve as basis for final end use.

Eleven possible optimisation solutions were identified from the models each with desirability index ranging from 0.909 to 0.936 , five of which were selected for verification experiment (Table 6) and for comparison of the sensory and proximate qualities with the control samples prepared using conventional method of cooking.

\section{Verification experiment}

Verification experiment conducted on the selected optimisation solutions showed that samples from all the five selected solutions produced at the identified optimisation conditions were adequately cooked (Table 9)

\section{Proximate Composition of Bambara Cooked by Conventional and Pressure Cooked methods}

The moisture, fat, ash, crude protein and carbohydrate contents of the samples ranged from 44.31, 2.24, 1.98, 24.30 and 20.74 to $50.58,3.02,2.84,25.85$ and 23.99 respectively. The Proximate results also (Table 10) revealed that the moisture, ash, and carbohydrate contents of the optimized solution 1 were not significant different $(p>0.05)$ from conventionally cooked samples and there were no significant difference $(p>0.05)$ in the protein contents of the samples cooked by both methods. These findings are in 
agreement with previous reports on the nutritional quality of Bambara nut. Hillocks et al.( 2011) and Bamshaiye et al., ( 2011) had reported that it has relatively lower protein contents than other legumes but higher proportion of methionine as a percentage of the protein than most other legumes. It was also reported that it contains essential and nonessential amino acids that conforms with FAO requirements. ( Aykroyd et al., 1982). As well as substantial quantity of vitamin A, thiamine, riboflavin, niacin, carotene, and trace quantities of ascorbic acid (Adeyeye et al., 2013 ; O yenuga, 1968).

\section{Sensory Properties of Bambara Cooked by Conventional and Pressure Cooked methods}

The colour, texture, aroma and general acceptance of the samples ranged from 4.67, $4.40,4.90$ and 5.23 to and 7.83, 6.83, 6.10 and 7.23 respectively with the pressure cooked samples having significantly $(\mathrm{p}<$ 0.05 ) higher colour, texture and general acceptance values. The sensory properties (Table 11) of the conventionally cooked samples were also not significantly different $(p>0.05)$ from the pressure cooked samples in terms of colour, texture, aroma and general acceptability but was significantly different in taste. 


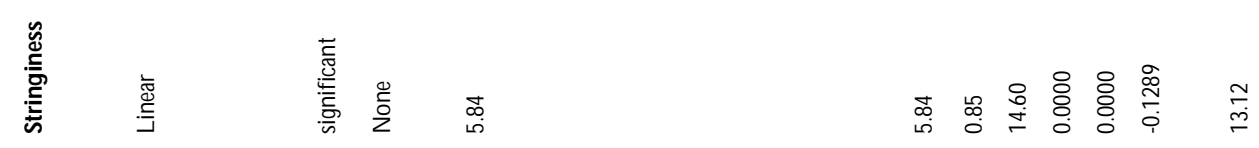

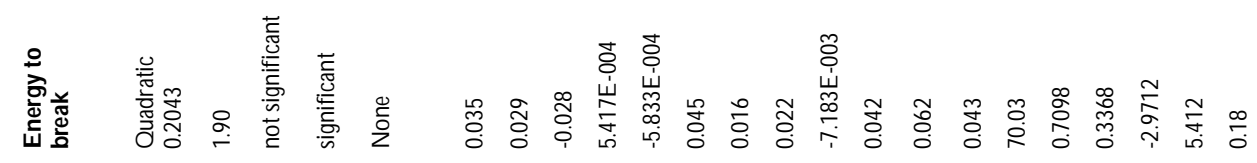

I IIH M

I

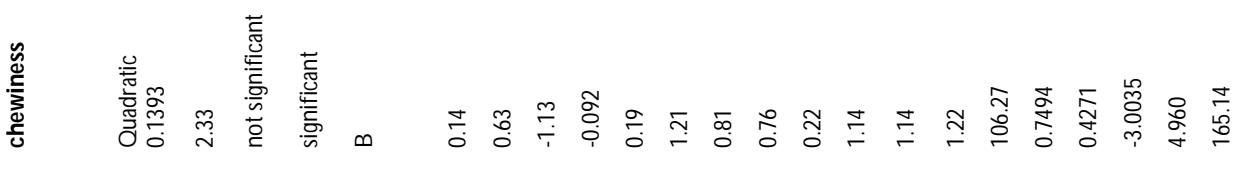

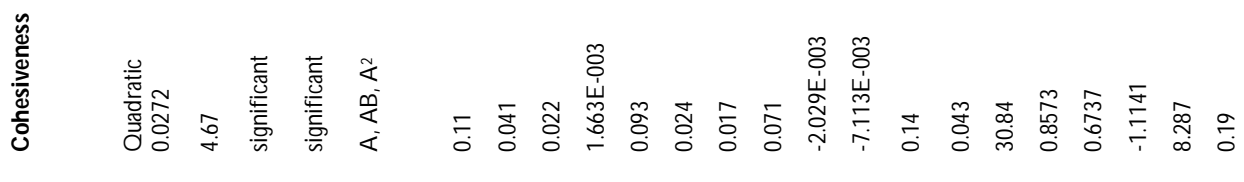

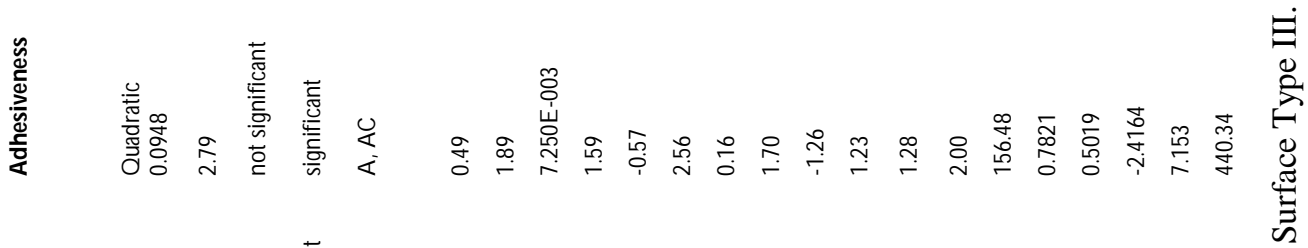

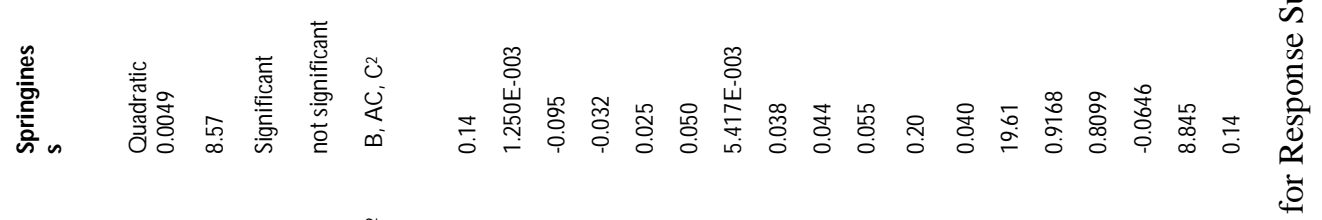

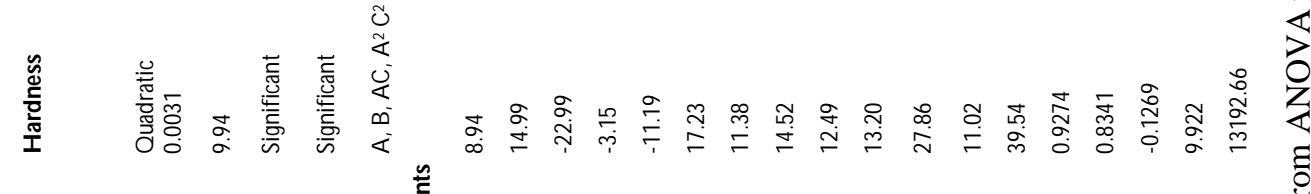

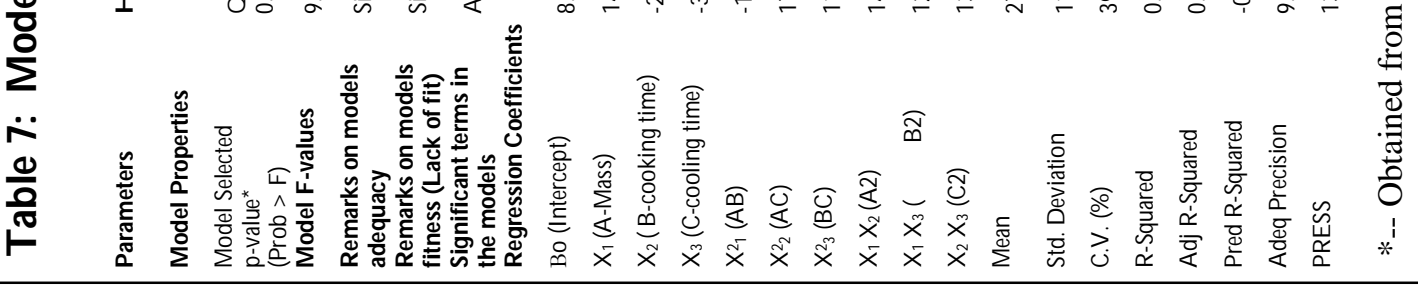




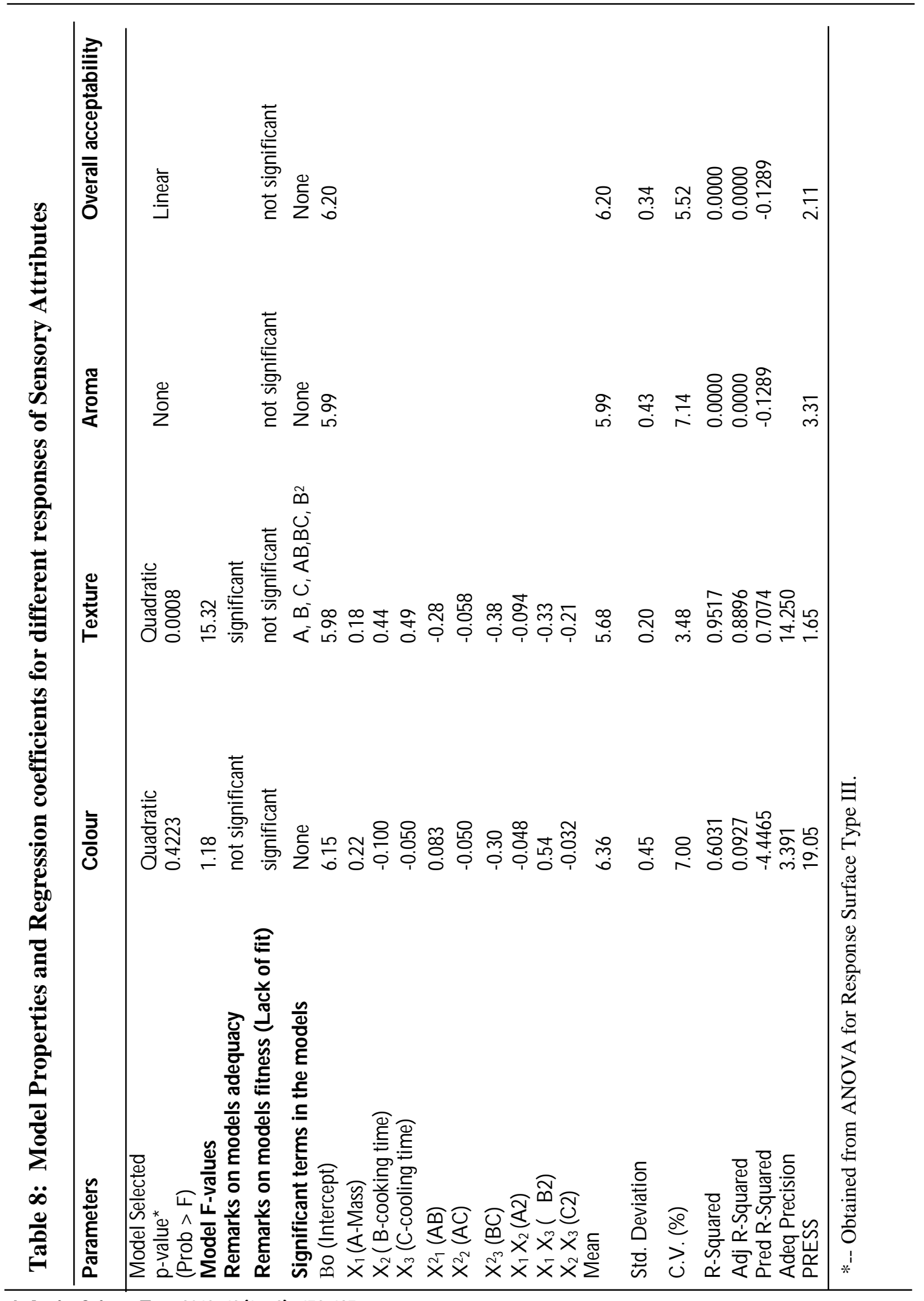

J. Agric. Sci. \& Env. 2019, 19(1\&2): 159-185 182 
EFFECTS OF CO OKING CONDITIO NS ON THE TEXTURE PROFILE, SENSORY ...

\section{CONCLUSION}

The aim of this study was to evaluate the effects of pressure cooking on the textural attributes of boiled Bambara using $\mathrm{Re}$ sponse Surface Methodology (RSM). This was done by assessing the effects of weight (Mass) of Bambara, cooking time, and post cooking time (Resident time) on the textural attributes of the boiled Bambara. Model characteristics and adequacy were explored; the proximate and sensory characteristics of samples from the optimized solutions were also compared with Bambara cooked by conventional methods. Eleven possible optimisation solutions were identified from the models each with desirability index range of 0.919 to 0.936 , five of which were used for the verification experiment and comparison of their proximate contents and sensory properties with the control samples. Two of the suggested solutions were suitable as the boiled Bambara samples produced at the identified optimisation conditions were adequately cooked but not over cooked and pulpy as the samples cooked by conventional method. This implied that Bambara of $527.62 \mathrm{~g}$ can be adequately cooked by boiling at cooking time and post cooking time 82.55 and 10.43 minutes respectively. In addition, exploration of the models suggested that the textural qualities of pressure cooked Bambara nuts would better assessed by hardness, springiness, cohesiveness and fracturability (Fig 1-5) while the sensory qualities would be explained by the sensory texture. This study has provided the baseline findings and necessities for the standardisation of pressure cooking of Bambara as a means of addressing the hard to cooked phenomenon usually associated with Bambara. The results of this study should be of interest to culinary engineers, food production managers and other personnel involve in equipment de- sign, foodservice research and mass production of food

\section{REFERENCES}

Adegunwa, M.0., Adebowale A.A., Bakare, H.A. and Kalejaiye.K.K. 2013 Effects of Treatments On The Antinutritional Factors And Functional Properties of Bambara Groundnut (Voandzeia Subterranea) Flour. Journal of Food Processing and Preservation. 38(4): 1875-1881

Adeyeye, E.I., O laleye, A.A. and Adesina, A.J. 2013 Food Properties of Hull, Dehulled and Whole Seed Samples of Bambara Groundnut (Vigna Subterranea L. Verdc). Glob. J. Sci. Frontier Res. Chem., 13(2), 928.

Adebowale KO and Lawal OS 2002, Effect of annealing and heat moisture conditioning on the physiological characteristics of bambara groundnut (Voandzeia subterranean) starch. Nahrung/ Food. 46: 311-316.

Aguilera, J.M. and Rivera, R. 1992. Hardto-cook defect in black beans: Hardening rates, water imbibition and multiple mechanism hypothesis. Food Res. Int. 1992, 25, 101-108

Amarteifio, J.0. and Moholo, D. 1998. The Chemical Composition of Four Legumes Consumed in Botswana. J. Food Comp. Analy. 1998, 11, 329-332.

Ani, D.P.; Umeh, J.C.; Ekwe, K.C. 2013. Bambara Groundnut as Panacea for Food Security: Profitability and Production Efficiency in Benue State, Nigeria. In Proc. 2nd Int. Symp. On Underutilized Plants Species "Crops for the Future - Beyond Food Security",. 979 (21): 217-224 
AOAC, 2005. O fficial Methods of Analysis, 16th ed. TheAssociation of Official Analytical Chemists, Virginia, Pp 1588.

Aykroyd, W.R., Doughty, J. and Ann 1982. W. Legumes in human nutrition. Food \& Agriculture Org., 1982, pp 45-53.

Bakare, H.A., Osundahunsi , O.F. Olusanya, J.0., Adegunwa, M.0. 2009. Optimization of Lye peeling of Breadfruit (Artocarpus comminis Frost) Using $\mathrm{Re}$ sponse Surface Methodology. Journal of Natural. Science. Engineering and Technology. 8(2):86-95.

Bakare, H.A., Adegunwa, M.0., Tossou, H. B. Durojaiye G. D., Sanni, I., Tijani A. 2018. Optimisation of the Processing Conditions on the Culinary Qualities of Pressure-Cooked Boiled Yam. Jarnal of Culinary Saiene and Tehndogy. 17 (6): 542-558

Bamshaiye, 0.M., Adegbola, J.A.; Bamishaiye, E.I. 2011. Bambara groundnut: An under-utilized nut in Africa. Adv. Agric. Biotechnol. 1: 60-72.

Boume M.C. 1978. Texture profile analysis. Food Technology 32:62-66, 72.

Boume M.C., Kenny J.F. and Bamard J. 1978. Computer assisted readout of data from texture profile analysis curves. Journal of Texture Studies 9: 481-494.

Coelho, C.M.M.; Bellato, C.d.M.; Santos, J.C.P.; O rtega, E.M.M.; Tsai, S.M. 2007. Effect of phytate and storage conditions on the development of the "hard-tocook' phenomenon in common beans. J. Sci. Food Agric., 87: 1237-1243.
Denis N'Dri Yao, Kouakou Nestor Kouassi , Daniela Enba , Francesca Scazzina , Nicoletta Pellegrini , and Maria Cristina Casiraghi . 2015. Nutritive Evaluation of the Bambara Groundnut Ci12 Landrace [Vigna subterranea (L.) Verdc. (Fabaceae)] Produced in Côte d'Ivoire. Int. J. Mol. Sci. 16: 21428-21441; doi:10.3390/

ijms160921428

Gancia, E., Filisetti, T.M.C.C., Udaeta, J.E.M. and Lajolo, F.M. 1998. Hard-tocook beans (Phasedus vulgaris): Involvement of phenolic compounds and pectates. J. Agric. Food Chem. 46, 2110- 2116.

Gupta, K.K. Sharma, A. and Sharma, R. 2007. Instrumental Texture Profile Analysis (TPA) of Shelled Sunflower Seed Caramel Snack Using Response Surface Methodology. Food Sci. Tech Int.13 (7):455-460

Hentges, D.L., Weaver, C.M. and Nielsen, S.S, 1991. Changes of Selected Physical and Chemical Components in the Development of the Hard-to-Cook Bean Defect. Journal of Food Science. 56(2): 436-442

Hillocks, R.J.; Bennett, C.; Mponda, O.M. 2011. Bambara nut: A review of utilisation, market potential and crop improvement. Afr. Crop Sci. J., 20(1), 1-16.

Kilcast, D., Subramaniam, P. 2000.The Stability and Shelf Life of Food. Cambridge, U.K: Woodhead Publishing Limited. Pp1612

Mubaiwa, J. Fogliano, V. Chidewe, C. and Linnemann, A.R. 2016 Hard-to-cook phenomenon in bambara groundnut (Vigna subterranea (L.) Verdc.) processing: O ptions to improve its role in providing food security. Food Reviews International, 33(2):167- 
EFFECTS OF CO OKING CONDITIONS ON THE TEXTURE PROFILE, SENSORY ...

194, D OI: $10.1080 / 87559129.2016 .1149864$

Mubaiwa, J., Fogliano, V., Chidewe, C., Padulosi, S., Hodgkin, T., Williams, J.T., Haq, N. 2002. Underutilized crops: Trends, Linnemann, A.R. 2017. Hard-to-cook phenomenon in bambara groundnut (Vigna subterranea (L.) Verdc.) processing: Options to improve its role in providing food security, Food Reviews International, 33: (2):167-194, DOI: 10.1080/ 87559129.2016.1149864

Mubaiwa, J. 2018. Managing the hard-tocook (HTC) phenomenon in Bambara groundnut (Vigna subterranea (L.) Verdc.) processing for resource limited communities in Zimbabwe, Unpublished Thesis submitted in fulfilment of the requirements for the degree of doctor at Wageningen University. D own loaded 28/ 08/ 2018.

Okpuzor, J., Ogbunugafor, H.A., O kafor, U., Sofidiya, M.0. 2010. Identification of protein types in Bambara nut seeds: Perspectives for dietary protein supply in developing countries. EXCLI J. 9, 17 -28. ISSN 1611-2156.

Onwuka, U.N.; Abasiekong, K.S. 2006. Production and evaluation of chocolate bars from roasted and unroasted african breadfruit, and bambara groundnut flours. J. Food Proc. Preserv., 30: 534-548.

Oyenuga, V.A. 1968. Nigeria's Foods and Feeding stuffs: Their chemistry and nutritive value. Ibadan University Press, pp 109.

challenges and opportunities in the 21st century. In Managing Plant Genetic Diversity (J.M.M. Engels, V. Ramanatha Rao, A.H.D. Brown and M.T. Jackson, eds.) pp. 323-338, International Plant $G$ enetic Resources Institute, CABI-IPG RI, Rome, Italy.

Plahar, W.A., Annan, N.T., Larweh, P.M., Golob, P., Swetman, T., Greenhaulgh, P., Coote, C., Hodges, R. 2002. Marketing and processing of bambara groundnuts (W. Africa). Crop Post Harvest Programme. Food Research Institute (FRI): Accra, Ghana. Pp 1-25

Rosenthal, A. J. 1999. Relation between instrumental and sensory measures of food texture. In: A.J. Rosenthal (ed.) Food Texture, Aspen Publishers, Gaithersburg, MA, pp. 1-17.

Scott-Blair, G 1958. Rheology in food research. Advances in Food Research. 8: 1-61

Stanley, D.W., Aguilera, J.M. 1985. A review of textural defects in cooked reconstituted legumes: the influence of structure and composition. J. Food Biochem., 9: 277-323.

Trinh, K. T., Glasgow, S. 2012. On the texture profile analysis test. A paper presented at a Conference in September 2012. Content following this page was uploaded by Tuoc Trinh on 23 October 2018.

(Manuscipt recived 4thApril, 2019; accepted 29thJune, 2020). 